\title{
Glutathione deficiency in alcoholics: risk factor for paracetamol hepatotoxicity
}

\author{
B H LAUTERBURG AND MARIA E VELEZ
}

From the Department of Clinical Pharmacology, University of Berne, Switzerland and Center for Experimental Therapeutics and Department of Psychiatry, Baylor College of Medicine, Houston, Texas, USA

Summary Patients chronically abusing ethanol are more susceptible to the hepatotoxic effects of paracetamol. This could be due to an increased activation of the drug to a toxic metabolite or to a decreased capacity to detoxify the toxic metabolite by conjugation with glutathione (GSH). To test these hypotheses paracetamol $2 \mathrm{~g}$ was administered to five chronic alcoholics without clinical evidence of alcoholic liver disease and five control subjects. The urinary excretion of cysteine- plus $\mathbf{N}$ acetyl-cysteine-paracetamol, the two major products of detoxification of the reactive metabolite of paracetamol, was not significantly higher in chronic alcoholics arguing against a substantially increased metabolic activation of paracetamol. Chronic alcoholics had significantly lower plasma concentrations of GSH than healthy volunteers, however $(4.35(1.89) \mu M \nu 8.48(2.68) \mu M$, $\mathbf{p}<0.05)$ before the administration of paracetamol, and plasma GSH reached lower concentrations in the alcoholics after paracetamol $(2.40(1.36) v 6.26(2.96) \mu \mathrm{M})$. In a group of patients with alcoholic hepatitis intrahepatic GSH was significantly lower than in patients with chronic persistent hepatitis and patients with non-alcoholic cirrhosis, suggesting that low plasma GSH in alcoholics reflects low hepatic concentrations of GSH. The data indicate that low GSH may be a risk factor for paracetamol hepatotoxicity in alcoholics because a lower dose of paracetamol will be necessary to deplete GSH below the critical threshold concentration where hepatocellular necrosis starts to occur.

Patients chronically abusing ethanol are more susceptible to the hepatotoxic effects of paracetamol such that relatively small doses of the analgesic may result in severe hepatic damage. ${ }^{12}$ Animal studies have shown that the toxicity of paracetamol arises as a consequence of the metabolic activation of the drug by the cytochrome P-450 system to a reactive metabolite. ${ }^{3}$ This metabolite is detoxified by intracellular glutathione (GSH), eventually resulting in cysteineand $\mathrm{N}$-acetylcysteine-paracetamol which are excreted in urine. Hepatocellular necrosis ensues when the capacity of the liver to resynthesize the consumed GSH and thus its capacity to detoxify the reactive metabolite is exceeded. ${ }^{+}$We have recently shown that even therapeutic doses of the analgesic markedly stimulate GSH turnover in man, ${ }^{5}$ but no direct evidence that paracetamol ingestion

Address for correspondence: Bernhard H Lauterburg, MD, Department of Clinical Pharmacology, University of Berne, Murtenstrasse 35, 3010 Berne, Switzerland.

Received for publication 12 April 1988. depletes hepatic stores of GSH has been obtained in man. Because repeat liver biopsies are not feasible in man the effect of a drug on the hepatic GSH status is difficult to assess. Based on data obtained in experimental animals, ${ }^{67}$ however, plasma GSH may reflect the intrahepatic concentration of GSH.

In view of the pathogenesis of paracetamol induced liver injury an increased formation of the toxic metabolite and/or a decreased detoxification could both account for the increased susceptibility of chronic alcoholics. Chronic ethanol consumption induces some cytochrome P-450- mediated processes in $\operatorname{man},{ }^{89}$ and this could result in an increased formation of the toxic metabolite and increased toxicity. On the other hand, a defective regulation of hepatic GSH homeostasis might decrease the capacity of chronic alcoholics to detoxify the toxic metabolite of paracetamol.

The aim of this study was to test these hypotheses by measuring plasma GSH as an index of hepatic GSH and the formation of the toxic metabolite after a 
non-toxic dose of paracetamol in patients chronically abusing ethanol.

\section{Methods}

\section{SUBJECTS}

In the first part of the study plasma GSH was determined after an overnight fast in chronic alcoholics and control subjects. Male alcoholics were recruited from an alcohol treatment programme. They all had been drinking heavily (estimated average consumption of $180 \mathrm{~g}$ ethanol/day) up to two days before the study which was done on the second day of their hospitalisation. The patients were not receiving any medication except for chlorodiazepoxide in some cases (the last dose of $10 \mathrm{mg}$ more than 10 hours before the study). This benzodiazepine is not conjugated with glutathione and is not known to induce drug metabolism within 48 hours of starting treatment. On physical examination none of the patients showed clinical evidence for alcoholic liver disease. All subjects had a normal serum albumin and serum bilirubin except for one whose bilirubin was $34 \mu \mathrm{mol} / \mathrm{l}$. Serum glutamic oxaloacetic transaminase was less than twice the upper limit of normal in all subjects except for two with 2.5 and 3.5 times raised values. Normal, healthy men served as controls. They denied consumption of ethanol in excess of $10 \mathrm{~g} /$ day and were not taking any medication.

In the second part of the study hepatic tissue was obtained from patients with alcoholic hepatitis undergoing percutaneous liver biopsy (Table 1) to document that low plasma GSH in alcoholics reflects low hepatic GSH. No medical indication for a liver biopsy was given in the subjects participating in the first and second part of the study. Plasma GSH was not measured in the biopsied patients because the equipment necessary for the rapid derivatisation of

Table 1 Concentration of glutathione in liver of patients with alcoholic hepatitis

\begin{tabular}{llllllll}
\hline & $\begin{array}{l}\text { GSH } \\
\text { gliver } \\
\text { Patient }\end{array}$ & $\begin{array}{l}\text { GSH } \\
\text { mg prot } \\
\text { nmol }\end{array}$ & GOT & $\begin{array}{l}\text { GPT } \\
\text { U/l }\end{array}$ & $\begin{array}{l}\text { Albu- } \\
\text { min } \\
\text { g/l }\end{array}$ & $\begin{array}{l}\text { Bili- } \\
\text { rubin } \\
\mu M\end{array}$ & $\begin{array}{l}\text { Alk } \\
\text { phos } \\
\text { Ull }\end{array}$ \\
\hline & & & $<40$ & $<40$ & & $<21$ & $<115$ \\
1 & $0 \cdot 58$ & 13.3 & 235 & 25 & 38 & 325 & 122 \\
$2^{*}$ & $0 \cdot 81$ & 11.0 & 130 & 11 & 26 & 53 & 214 \\
3 & $0 \cdot 86$ & 10.4 & 222 & 71 & 27 & 63 & 355 \\
4 & $1 \cdot 15$ & 8.0 & 99 & 15 & 34 & 49 & 475 \\
$5^{*}$ & 1.34 & 24.7 & 127 & 16 & 26 & 20 & 322 \\
$6^{*}$ & 1.59 & 12.7 & 58 & 19 & 25 & 53 & 268 \\
$7^{*}$ & 1.78 & 21.8 & 85 & 69 & 26 & 23 & 168 \\
$8^{*}$ & 2.28 & 17.8 & 50 & 32 & 26 & 20 & 120 \\
\hline
\end{tabular}

*Histology showed cirrhosis in addition to alcoholic hepatitis. plasma sulphydryls was not available on the wards. Patients with chronic persistent hepatitis and nonalcoholic cirrhosis (cirrhosis as a result of chronic active liver disease, cryptogenic cirrhosis) who had a percutaneous biopsy for diagnostic purposes, and patients without liver disease undergoing open biopsy at the time of cholecystectomy provided control values for intrahepatic GSH.

In the third part of the study the effect of paracetamol on plasma GSH was determined in five alcoholics and five healthy volunteers. A heparin lock was placed in a vein of the forearm for repeat blood sampling. The subjects who had been fasting for 10 hours then received $2 \mathrm{~g}$ paracetamol dissolved in lemonade between 8 and $9 \mathrm{am}$, and blood was obtained at hourly intervals for four hours for the determination of plasma GSH. Pilot studies had shown that plasma GSH varies by less than $10 \%$ over four hours. In order to estimate the metabolic activition of paracetamol to the toxic metabolite, urine was collected for six hours.

The study was approved by the Institutional Review Board and all subjects gave informed consent to participate.

\section{ANALYTICAI. METHODS}

Blood was immediately centrifuged at $3000 \mathrm{~g}$ for two minutes. None of the samples was visibly haemolysed. Within three minutes of collection $200 \mu \mathrm{l}$ plasma were added to $20 \mu \mathrm{l} 5 \mathrm{mM}$ monobromobimane in acetonitrile and penicillamine was added as an internal standard. After three minutes proteins were precipitated with $40 \mu \mathrm{l} 20 \%$ perchloric acid. After centrifugation the protein free supernatant was analysed by reverse phase high performance liquid chromatography and fluorometric detection ${ }^{11}$ using $0.005 \mathrm{M}$ octanesulphonic acid $/ 1 \%$ acetic acid $/ 5 \%$ acetonitrile as the mobile phase. Standard curves were obtained each day by spiking plasma samples with known amounts of cysteine and GSH.

Urinary metabolites of paracetamol were measured by high performance liquid chromatography as described by Corcoran et al. " Glutathione in liver biopsies was measured by the method of Tietze."'

Because the hypothesis that the values of plasma GSH were normally distributed could not be rejected at the $95 \%$ confidence level, the statistical analysis of the group means of the time course study of plasma GSH was done by paired $t$-test, and statistical differences between alcoholics and controls were assessed by 2 -sided $t$-test.

\section{Results}

As shown in Figure 1 the plasma concentration of 


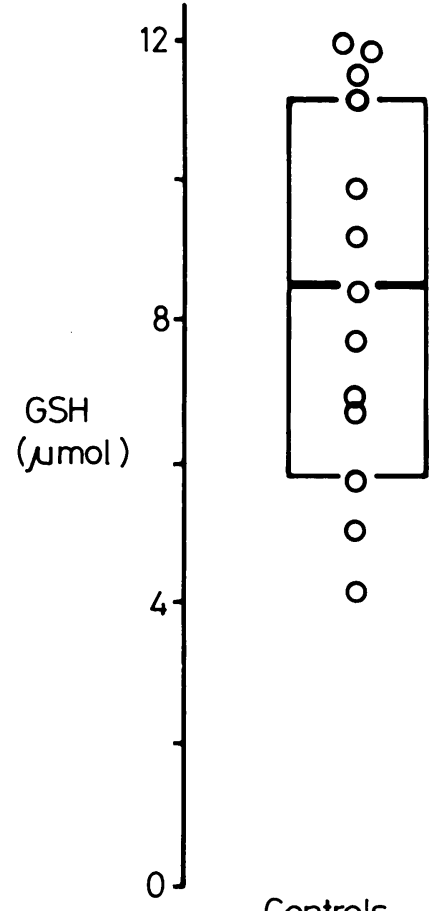

\section{Controls}

Table 2 Glutathione in human liver

\begin{tabular}{|c|c|c|}
\hline & $\mu \mathrm{mol} / \mathrm{g}$ wet weight & nmol/mg protein \\
\hline Alcoholic hepatitis (8) & $1.30(0.57)^{*}$ & $15 \cdot 0(5 \cdot 9)$ \\
\hline $\begin{array}{l}\text { Normal liver (3) (surgica! } \\
\text { biopsies) }\end{array}$ & $4.62(0.79)$ & $39.9(14.7)$ \\
\hline Chronic persistent hepatitis $(5$ & $3.79(1.73)^{\dagger}$ & $32 \cdot 2(15 \cdot 2) \div$ \\
\hline Non-alcoholic cirrhosis (7) & $2.39(1.64)$ & $32 \cdot 6(16 \cdot 7) \ddagger$ \\
\hline
\end{tabular}

*mean (SD), the number of patients are indicated in brackets: $t p<0 .(01 v$ alcoholic hepatitis: $\ddagger p<0.05 v$ alcoholic hepatitis; values mean (SD).

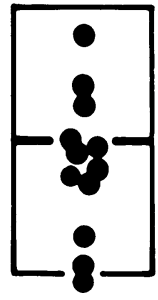

decreased by approximately $50 \%$ in alcoholics.

The time course of the plasma concentration of GSH after the administration of paracetamol to five alcoholics and five control subjects is shown in Figure 2. After the administration of the drug the plasma concentration of GSH decreased from 8.37 (2.65) $\mu \mathrm{M}$ (mean (SD)) to $6.26(2.96) \mu \mathrm{M}$ at three hours $(\mathrm{p}<0.02$ by paired $t$-test $)$ in normal volunteers. In the alcoholics the values at two hours $(3 \cdot 10(1.83) \mu \mathrm{M}$, $\mathrm{p}<0.02)$ and three hours $(2.40(1.36) \mu \mathrm{M}, \mathrm{p}<0.05)$ were significantly lower than the baseline GSH concentration of $4.66(1.87) \mu \mathrm{M}$ and significantly $(\mathrm{p}<0.05)$ lower than the corresponding values in the

\section{Alcoholics}

Fig. 1 Concentration of glutathione in plasma in chronic alcoholics and healthy volunters. Mean (SD) indicated by hars.

GSH was significantly $(\mathrm{p}<0 \cdot(05)$ lower in alcoholics $(4.35(1.89) \mu \mathrm{M}$, mean (SD)) than in healthy volunteers $(8.48(2.68) \mu \mathrm{M})$. The values in the two patients with biochemical evidence for alcoholic liver disease were comparable with the other patients. In contrast to $\mathrm{GSH}$, the plasma concentration of free cysteine was similar in the alcoholics $(9.71(2.42) \mu \mathrm{M})$ and the controls $(9 \cdot 46(2 \cdot 29) \mu \mathrm{M})$.

To test the hypothesis that low plasma GSH might reflect low intrahepatic GSH as it does in experimental animals, ${ }^{\circ}$ hepatic GSH was measured in a group of alcoholic patients in whom a percutaneous liver biopsy was indicated for medical reasons. The biopsied patients all had histological evidence of alcoholic hepatitis with and without cirrhosis, and as a group had more severe liver disease (Table 1) than the alcoholic subjects in whom plasma GSH was measured. The hepatic concentration of GSH in these alcoholic patients was significantly lower than in patients without liver disease and patients with a mild inflammatory process or non-alcoholic cirrhosis (Table 2). In the four patients with GOT activities of less than 2.5 times the upper limit of normal the hepatic concentration of GSH per mg protein was not higher than in the other patients. Both, the plasma and the hepatic concentrations of GSH, were thus

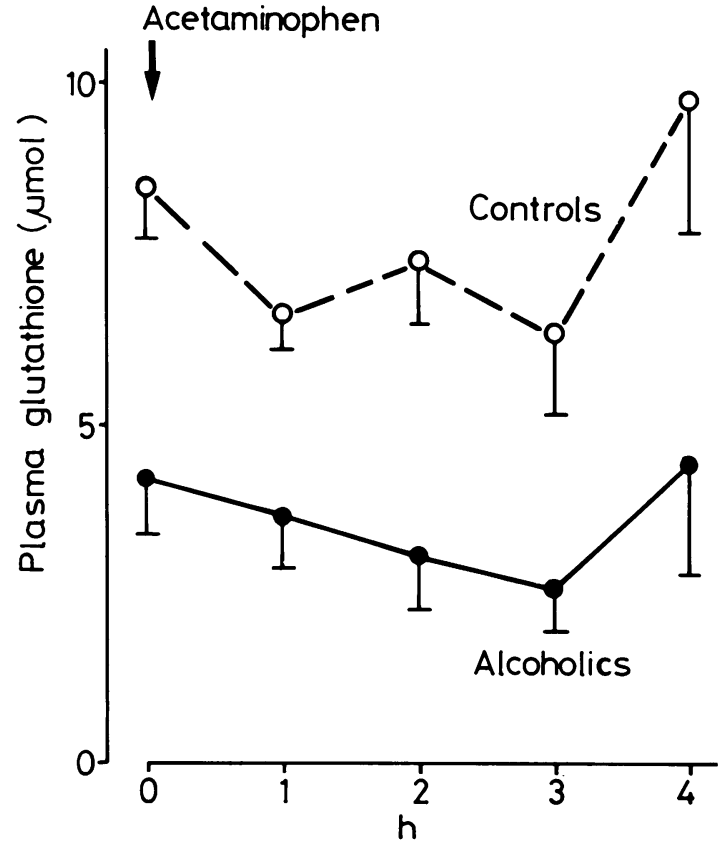

Fig. 2 Concentration of glutathione in plasma in five healthy volunteers and five chronic alcoholics before and after ingestion of $2 \mathrm{~g}$ of paracetamol (mean (SE)). The values at $0,1,2$, and $3 \mathrm{~h}$ are significantly lower in the alcoholics $(p<0 \cdot 05)$. 
Table 3 Metabolites of paracetamol excreted in urine ( $\mu$ mol in six hours)

\begin{tabular}{|c|c|c|c|c|c|c|}
\hline & Sulphate & $\begin{array}{l}\text { Glucuro- } \\
\text { nide }\end{array}$ & $\begin{array}{l}\text { Acetamino- } \\
\text { phen }\end{array}$ & $\begin{array}{l}\text { Mercaptu- } \\
\text { ric acid }\end{array}$ & Cysteine & $\begin{array}{l}\text { Urine } \\
\text { vol } \\
\text { ml }\end{array}$ \\
\hline \multicolumn{7}{|c|}{ Controls } \\
\hline 1 & 1599 & 1829 & 184 & 121 & 96 & 365 \\
\hline 2 & 2445 & 5702 & 229 & 147 & 143 & 385 \\
\hline 3 & 1581 & 2448 & 180 & 160 & 111 & 105 \\
\hline 4 & 1656 & 2734 & 155 & 115 & 89 & 470 \\
\hline \multirow[t]{2}{*}{5} & 1229 & 1177 & 83 & 102 & 75 & 75 \\
\hline & $\begin{array}{l}1702 \\
(448)\end{array}$ & $\begin{array}{c}2778 \\
(1741)\end{array}$ & $\begin{array}{l}166 \\
(54)\end{array}$ & $\begin{array}{l}129 \\
(24)\end{array}$ & $\begin{array}{l}103 \\
(26)\end{array}$ & \\
\hline \multicolumn{7}{|c|}{ Alcoholics } \\
\hline 1 & 670 & 970 & 37 & 53 & 30 & 180 \\
\hline 2 & 2363 & 2713 & 132 & 173 & 163 & 625 \\
\hline 3 & 2068 & 3630 & 195 & 198 & 172 & 550 \\
\hline 4 & 4959 & 6216 & 384 & 290 & 264 & 435 \\
\hline \multirow[t]{3}{*}{5} & 1021 & 3082 & 72 & 265 & 216 & 155 \\
\hline & 2216 & 3322 & 164 & 196 & 169 & \\
\hline & $(1687)$ & (1899) & (137) & (93) & (87) & \\
\hline
\end{tabular}

Values mean (SD).

controls. The plasma concentration of cysteine decreased to $5 \cdot 0(2 \cdot 6) \mu \mathrm{M}$ in the normal volunteers $(\mathrm{p}<0.05)$ and to $8.3(2.3) \mu \mathrm{M}$ in the alcoholics (not significant).

The urinary excretion of metabolites of paracetamol during the critical first six hours is shown in Table 3. There was no statistically significant difference in the recovery and the relative proportions and absolute amounts of metabolites between alcoholics and controls.

\section{Discussion}

Our data indicate that chronic excessive ethanol consumption is associated with decreased circulating concentrations of GSH. Either an increase in the catabolism of plasma GSH or a decreased release of GSH by the liver, possibly because of malnutrition or a direct effect of ethanol, could account for this observation. Degradation of GSH by gamma glutamyl transferase, an enzyme the activity of which is commonly found to be raised in serum of alcoholic patients, is the major route of catabolism of GSH. An increase in the activity of gamma glutamyltransferase, however, does not measurably increase the clearance of plasma GSH. ${ }^{13}$ Low plasma GSH in the presence of decreased concentrations of GSH in the liver of alcoholics even in the presence of good nutrition ${ }^{14}$ suggest a decreased efflux of GSH from the liver. In rats the liver is the major source of plasma $\mathrm{GSH}^{15}$ and the plasma concentration of the tripeptide reflects its intrahepatic concentration. ${ }^{6} \mathrm{~A}$ similar relationship can be inferred from the observation that hepatic and plasma GSH are decreased by approximately $50 \%$ in chronic alcoholics. A comparable decrease in hepatic GSH has been reported in patients with alcoholic fatty liver, ${ }^{14}$ whose clinical status might correspond better to the subjects in whom we measured plasma GSH.

The interpretation that plasma GSH reflects intrahepatic GSH also in man is further supported by the decrease in plasma GSH following paracetamol. The dose of paracetamol of which approximately $8 \%$ or $1060 \mu \mathrm{mol}$ will be activated to the toxic metabolite requires the same amount of GSH for its detoxification. Assuming a liver weight of $1500 \mathrm{~g}$ this consumption of GSH will decrease the concentration of intrahepatic GSH from approximately $4 \mu \mathrm{mol} / \mathrm{g}$ to $3.3 \mu \mathrm{mol} / \mathrm{g}$. The approximately $25 \%$ decrease in plasma GSH seen in our subjects (Fig. 2) is consistent with this intracellular depletion of GSH. The compensatory stimulation of hepatic GSH synthesis ${ }^{5}$ increases the consumption of cysteine and could thus explain the decrease in plasma cysteine. The lesser fall in plasma cysteine seen in alcoholics could possibly be due to a decreased capacity to stimulate GSH synthesis in response to a stress on the hepatic GSH pool.

The mechanism by which chronic alcoholism decreases hepatic glutathione in man is not clear at present. In rats, ethanol acutely depletes GSH, most likely by inhibiting its synthesis. ${ }^{16}$ After chronic administration of ethanol to experimental animals, the hepatic concentration either decreases, increases, or remains unchanged. ${ }^{17-19}$ The administration of a nutritionally adequate diet, however, together with ethanol in these animal studies may not be a good model for our patient population who required treatment in a facility. In this population, malnutrition ${ }^{20}$ as well as a specific effect of ethanol on GSH homeostasis could be responsible for the decrease in GSH. Whatever the mechanism, a decreased availability of GSH in the liver and the circulation might render alcoholics more susceptible to the toxic effects of certain xenobiotics and reactive oxygen species.

Based on experiments with rodents ${ }^{2122}$ enzyme induction by chronic ethanol consumption has generally been thought to be the major factor explaining the increased hepatotoxicity of paracetamol in chronic alcoholics. Enzyme induction would contribute to the toxicity of paracetamol during the first few hours after ingestion of the drug when the rate of formation of the toxic metabolite is highest. ${ }^{23}$ In agreement with data reported by other investigators ${ }^{24}$ however, the alcoholics participating in our study did not excrete significantly more cysteine- and $\mathrm{N}$-acetyl-cysteine-paracetamol, the major metabolites of the toxic intermediate, during that critical period of time. 
In conclusion, the concentrations of GSH in liver and plasma are significantly lower in alcoholics, and plasma GSH reaches lower levels after the ingestion of a therapeutic dose of paracetamol. In experimental animals covalent binding and hepatocellular necrosis is seen in vivo when the hepatic concentration of GSH falls below 0.5 to $1.0 \mu \mathrm{mol} / \mathrm{g}$. ${ }^{+}$Provided that plasma GSH reflects intrahepatic GSH also in man as our data suggest, a lower dose of paracetamol will be necessary to deplete GSH in alcoholics below the critical threshold concentration where hepatocellular necrosis starts to occur.

This study was supported by the Alcoholic Beverage Medical Research Foundation and by grant no 3.824.0.84 from the Swiss National Foundation for Scientific Research and grant no GM34120 from the National Institute of General Medical Sciences.

\section{References}

1 McClain CJ, Kromhout JP. Peterson FJ, Holtzman JL. Potentiation of paracetamol hepatotoxicity by alcohol. JAMA 1980; 244: 251-3.

2 Licht H. Seeff LB, Zimmermann HJ. Apparent potentiation of acetaminophen hepatotoxicity by alcohol. Ann Intern Med 1980; 92: 511.

3 Mitchell JR. Jollow DJ. Potter WZ. David DC. Gillette JR, Brodie BB. Paracetamol-induced hepatic necrosis. I. Role of drug metabolism.J Pharmacol Exp Ther 1973; 187: 185-94.

4 Mitchell JR, Jollow DJ, Potter WZ, Gillette JR, Brodie BB. Paracetamol-induced hepatic necrosis. IV. Protective role of glutathione. J Pharmacol Exp Ther 1973; 187: $211-7$.

5 Lauterburg BH, Mitchell JR. Therapeutic doses of paracetamol stimulate the turnover of cysteine and glutathione in man. J Hepatol 1987: 4: 206-11.

6 Adams JD. Lauterburg BH, Mitchell JR. Plasma glutathione and glutathione disulfide in the rat: regulation and response to oxidative stress. J Pharmacol Exp Ther 1983; 227: 749-54.

7 Ookhtens M. Hobdy K. Corvasce MC. Aw TY. Kaplowitz N. Sinusoidal efflux of glutathione in the perfused rat liver. J Clin Invest 1985; 75: 258-65.

8 Misra PS, Lefevre A. Ishii H. Rubin E, Lieber CS. Increase of ethanol. meprobamate and pentobarbital metabolism after chronic ethanol administration in man and in rats. Am J Med 1971: 51: 346-51.

9 Kater RMH. Roggin G. Tobon F, Zieve P. Iber FL.
Increased rate of clearance of drugs from the circulation of alcoholics. Am J Med Sci 1969; 258: 35-9.

10 Newton GL. Dorian R, Fahey RC. Analysis of biological thiols: derivatization with monobromobimane and separation by reverse phase high performance liquid chromatography. Anal Biochem 1981; 114: 383-7.

11 Corcoran GB, Todd EL, Racz WH, Hughes H, Smith CV. Mitchell JR. Effects of N-Acetylcysteine on the disposition and metabolism of paracetamol in mice. J Pharmacol Exp Ther 1984; 232: 857-63.

12 Tietze F. Enzymatic method for quantitative determination of nanogram amounts of total and oxidized glutathione. Anal Biochem 1969; 27: 502-22.

13 Burgunder M, Lauterburg BH. Decreased production of glutathione in patients with cirrhosis. Eur J Clin Invest 1987; 17: 408-14.

14 Shaw S, Rubin KP, Lieber CS. Depressed hepatic glutathione and increased diene conjugates in alcoholic liver disease. Dig Dis Sci 1983; 28: 585-9.

15 Lauterburg BH, Adams JD, Mitchell JR. Hepatic glutathione homeostasis in the rat: efflux accounts for glutathione turnover. Hepatology 1984; 4: 586-90.

16 Lauterburg BH. Davies S, Mitchell JR. Ethanol suppresses hepatic glutathione synthesis in rats in vivo. J Pharmacol Exp Ther 1984; 230: 7-11.

17 Morton S, Mitchell MC. Effects of chronic ethanol feeding on glutathione turnover in the rat. Biochem Pharmacol 1985; 34: 1559-63.

18 Hétu C, Yelle L, Joly JG. Influence of ethanol on hepatic glutathione content and on the activity of glutathione S-transferases and epoxide hydrase in the rat. Drug Metab Disp 1982; 10: 246-50.

19 Guerri C, Grisolia S. Influence of prolonged ethanol intake on the levels and turnover of alcohol and aldehyde dehydrogenases and glutathione. Adv Exp Med Biol 1980; 126: 365-84.

20 Mendenhall ChL, Anderson S, Weesner RE, Goldberg SJ, Crolic KA. Protein-calorie malnutrition associated with alcoholic hepatitis. Am J Med 1984; 76: 211-22.

21 Peterson FJ. Holloway DE, Erickson RR, Duquette $\mathrm{PH}$, McClain CJ, Holtzman JL. Ethanol induction of paracetamol toxicity and metabolism. Life Sci 1908; 27: 1705-11.

22 Sato C, Matsuda Y, Lieber CS. Increased hepatotoxicity of acetaminophen after chronic ethanol consumption in the rat. Gastroenterology 1981; 80: 140-8.

23 Slattery JT, Wilson JM, Kalhorn TF, Nelson SD. Dosedependent pharmacokinetics of paracetamol: Evidence of glutathione depletion in humans. Clin Pharmacol Ther 1987; 41: 413-8.

24 Prescott LF, Critchley JAJH. Drug interactions affecting analgesic toxicity. Am J Med 1983; 75: 113-6. 